\title{
Decreasing the overall environmental impact of the Dutch diet: how to find healthy and sustainable diets with limited changes
}

\author{
Gerard FH Kramer ${ }^{1}$, Marcelo Tyszler ${ }^{2}$, Pieter van't Veer ${ }^{3}$ and Hans Blonk ${ }^{1, *}$ \\ 'Blonk Consultants, Gravin Beatrixstraat 34, 3111 PX Gouda, The Netherlands: ${ }^{2}$ Department of Sustainable \\ Economic Development, Royal Tropical Institute (KIT), Amsterdam, The Netherlands: ${ }^{3}$ Division of Human Nutrition, \\ Wageningen University, Wageningen, The Netherlands
}

Submitted 14 March 2016: Final revision received 9 November 2016: Accepted 8 February 2017: First published online 20 March 2017

\begin{abstract}
Objective: To find diets optimised on nutrition and environmental impact close to the current Dutch diet and to identify the most effective and acceptable options for mitigating environmental impact.

Design: Linear programming was used to optimise diets of Dutch men and women aged 9-69 years, divided into ten age-gender groups. The analysis included nutrient composition, a metric for popularity and life cycle assessments of 207 food products. Greenhouse gas emissions, fossil energy use and land occupation were used to calculate a weighted score for the overall environmental impact. Optimised diets were solutions that minimised changes to the current diet while satisfying all nutritional constraints, with stepwise reductions in environmental impact.

Setting: The Netherlands.

Subjects: Dutch children and adults aged 9-69 years.

Results: Meat was always reduced. Vegetable, fruit and dairy contents remained similar, while bread, fatty fish and legumes increased. The extent of changes depended on age and gender. Beverages were not heavily reduced. Nutrients critical for the outcome were $\alpha$-linoleic acid, retinol, Ca, Na, Se, dietary fibre, SFA, thiamin and $\mathrm{Fe}$ (women of childbearing age). Total protein, essential amino acids and carbohydrates were not critical.

Conclusions: Reducing meat is the most effective option for lowering the environmental impact of diets in all age-gender groups. Reducing alcoholic and non-alcoholic beverages is another option. Leaving out fish and dairy products are not. The differences in nutritional requirements related to age and gender have a significant effect on the composition of the optimised diets.
\end{abstract}

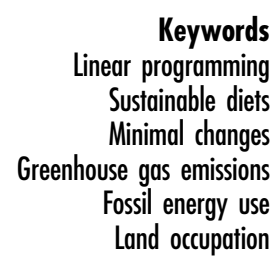

There is strong evidence that food production and consumption are important sources of environmental impact $^{(1,2)}$. A growing body of research ${ }^{(3,4)}$ from Europe ${ }^{(5)}$, the USA ${ }^{(6,7)}$ and elsewhere suggests that a change in dietary pattern such as adopting a vegetarian diet is an option for reducing environmental impact. A key challenge is that a proposed diet should not only reduce environmental impact but also meet nutritional requirements. As several authors have shown, such diets can be difficult to design ${ }^{(8-12)}$. Moreover, new diets should consider dietary preferences in order to be acceptable for consumers. The current paper presents an innovative method for designing optimised diets that incorporates environmental performance, nutritional requirements and dietary preferences.

Composing healthy diets with a lower environmental impact is quite complex, as every food contains a different mixture of nutrients and has different values for environmental indicators. For example, some studies have focused on finding alternatives to animal protein, because reducing animal-based products should deliver big reductions in the total environmental impact ${ }^{(13,14)}$. However, this not only ignores alternative ways to reduce environmental impact, but also overlooks the nutritional consequences. Animal-based products make a significant contribution to the intake of essential nutrients like Fe, Se, $\mathrm{Zn}, \mathrm{Ca}$, thiamin, vitamin $\mathrm{B}_{12}$ and vitamin $\mathrm{D}^{(15)}$.

Previous research ${ }^{(10,11)}$ has approached the problem of designing improved diets by using linear programming. When incorporating dietary preferences, percentage changes to certain foods or food groups were limited and metrics for popularity of food products were included. However, these studies focused primarily on minimising greenhouse gas emissions (GHGE), only one of the relevant environmental indicators associated with food consumption ${ }^{(1)}$. 
We contribute to the literature by formulating the optimisation problem as a minimisation of the changes to the current average diet, with nutritional requirements and environmental targets as constraints. Thereby, we take dietary preferences into account and can quantify the extent of deviation from the current diet. By gradually lowering the target for the overall environmental impact of the diet, we can monitor the evolution of shifts in the diet over the whole range, with a particular focus on the most effective changes: small changes with a high mitigation potential. Moreover, we incorporate two other environmental indicators: fossil energy use (FEU) and land occupation (LO). We also demonstrate that differences in age and gender influence the outcome of optimisations. Lessons learnt from the present study have a broader scope, due to similarities between the Dutch diet and diets across Europe ${ }^{(16,17)}$.

\section{Methods}

\section{Study population}

The Dutch National Food Consumption Survey 2007-2010 (DNFCS) ${ }^{(15,18)}$ provided the study population for our analyses. These data were collected from 3819 subjects by means of $24 \mathrm{~h}$ recalls on two non-consecutive days. Consumption of 1599 foods was reported. The data were grouped by gender in five age groups. We report and discuss the results for males and females aged 31-50 years and some of the results for those aged 51-69 years. Results for all remaining age groups (9-13, 14-18, 19-30 and 51-69 years) by gender are included in the online supplementary material, Supplemental Fig. 1.

\section{Food products and current diet}

Our analyses were based on 207 out of the 1599 products consumed during the DNFCS ${ }^{(18)}$. The selection of products was based on the ranking in the total weight consumed by the population and the availability of environmental data. In addition, we included a few plant-based alternatives for products of animal origin, such as fortified soya drink, legumes and fortified meat replacers. The selected products made up a large part of the total intake of the survey population, representing $77 \%$ of the consumed weight and $56 \%$ of the energy intake before scaling, as explained below.

We derived a condensed average weekly diet (current diet) for each of the age and gender groups. Food products providing less than $1 \%$ of the weekly energy intake of a food group were removed and the remaining ones were scaled proportionally to reach the average energy intake in the survey (isoenergetic). The overall nutrient composition of these derived diets was similar to the observed average intake from the full range of food products, but not a perfect match (see online supplementary material, Supplemental Table 1).

To guarantee a varied $\operatorname{diet}^{(19)}$, we set additional constraints on the maximum amount of each product in a weekly diet. For example, each type of vegetable was limited to a maximum of $400 \mathrm{~g} /$ week.

\section{Nutrient data}

The macro- and micronutrient composition of foods was obtained from the Dutch Food Composition Database ${ }^{(20)}$. The essential amino acid contents were obtained from the US Department of Agriculture Database ${ }^{(21)}$ by matching each Dutch product with the most similar product from the USA.

\section{Nutrient requirements}

Nutrient requirements used as restrictions in the model were compiled from national ${ }^{(22,23)}$ and international ${ }^{(24)}$ requirements for energy and macro- and micronutrients (Table 1). Specific values for age and gender groups were determined in close cooperation with the Netherlands Nutrition Centre (Voedingscentrum, The Hague). We applied the Recommended Dietary Allowance or Adequate Intake as the lower limit and the Tolerable Upper Intake Level as the upper limit in the model. Energy intake was limited to a maximum of $10 \mathrm{kcal} / \mathrm{d}(41.84 \mathrm{~kJ} / \mathrm{d})$ deviation from the current diet to prevent reduction of the environmental impact simply by reducing dietary energy intake. The average body weight observed in the DNFCS was used to determine the requirement for each essential amino $\operatorname{acid}^{(24)}$.

\section{Environmental indicators}

Representative data for the computation of GHGE, FEU and LO were collected from various sources ${ }^{(25)}$ and modelled from cradle to grave, making adjustments to the mass balance during the consumer phase to account for the edible parts, raw to cooked ratios ${ }^{(18)}$ and avoidable waste by consumers in the Netherlands ${ }^{(26)}$. Although GHGE, FEU and LO can individually support the analysis of sustainability, there are clear trade-offs between them. For example, it is possible to reduce LO considerably by using higher inputs of energy, as in greenhouse horticulture instead of open field cultivation. The life cycle assessment literature shows that to deal with these issues, widespread use is made of the ReCiPe method ${ }^{(27)}$, a single score environmental indicator which includes GHGE, FEU, LO and fifteen other indicators. Since GHGE, FEU and LO account for approximately $90 \%$ of the total ReCiPe score in food products ${ }^{(28)}$, we used a partial ReCiPe score. Including other impact categories would require more data, with minimal additional benefit. We combined the characterisation, normalisation and weighting factors defined in the ReCiPe method and calculated the partial ReCiPe score ( $p$ ReCiPe) as an indicator of overall environmental impact using the following expression:

$p$ ReCiPe $=0.0459 \times \mathrm{GHGE}+0.0025 \times \mathrm{FEU}+0 \cdot 0439 \times \mathrm{LO}$,

where GHGE is in $\mathrm{kg} \mathrm{CO} 2$ equivalents/ $\mathrm{kg}$, FEU is in $\mathrm{MJ} / \mathrm{kg}$ and $\mathrm{LO}$ is in $\mathrm{m}^{2} \times$ year $/ \mathrm{kg}$. 
Table 1 Selection of included nutrient requirements applied as lower and upper limits in the linear programming model

\begin{tabular}{|c|c|c|c|c|c|c|c|c|c|c|}
\hline & \multicolumn{2}{|c|}{ Men aged $31-50$ years } & \multicolumn{2}{|c|}{ Men aged $51-69$ years } & \multicolumn{2}{|c|}{ Women aged $31-50$ years } & \multicolumn{2}{|c|}{ Women aged $51-69$ years } & \multicolumn{2}{|c|}{ References } \\
\hline & Lower & Upper & Lower & Upper & Lower & Upper & Lower & Upper & Lower & Upper \\
\hline \multicolumn{11}{|l|}{ Macronutrients } \\
\hline Energy $(\mathrm{kcal})^{\star}$ & 2620 & 2640 & 2420 & 2440 & 1982 & 2002 & 1845 & 1865 & Al & Al \\
\hline Protein total (g) & 59 & 156 & 60 & 144 & 50 & 125 & 52 & 119 & (22) & (22) \\
\hline Fat total $(\mathrm{g})$ & 56 & 111 & 51 & 102 & 44 & 89 & 42 & 84 & (22) & (22) \\
\hline SFA (g) & - & 28 & - & 26 & - & 22 & - & 21 & & (22) \\
\hline PUFA $(g)$ & - & 33 & - & 31 & - & 27 & - & 25 & & (22) \\
\hline a-Linoleic acid (g) & $2 \cdot 8$ & - & 2.6 & - & $2 \cdot 2$ & - & $2 \cdot 1$ & - & (22) & \\
\hline Carbohydrates total (g) & 250 & 438 & 230 & 403 & 200 & 350 & 190 & 333 & (22) & (22) \\
\hline Fibre (g) & 40 & - & 35 & - & 30 & - & 25 & - & (51) & \\
\hline $\mathrm{DHA}+\mathrm{EPA}(\mathrm{mg})$ & 450 & 1000 & 450 & 1000 & 450 & 1000 & 450 & 1000 & (19) & (19) \\
\hline \multicolumn{11}{|l|}{ Vitamins } \\
\hline Retinol activity equivalents $(\mu \mathrm{g})$ & 900 & 3000 & 900 & 3000 & 700 & 3000 & 700 & 3000 & (23) & \\
\hline Thiamin (mg) & $1 \cdot 1$ & - & 1.1 & - & $1 \cdot 1$ & - & $1 \cdot 1$ & - & (23) & (23) \\
\hline Riboflavin (mg) & 1.5 & - & 1.5 & - & $1 \cdot 1$ & - & $1 \cdot 1$ & - & (23) & (23) \\
\hline Niacin (mg) & 17 & - & 17 & - & 13 & - & 13 & - & (23) & (23) \\
\hline Vitamin $B_{6}(\mathrm{mg})$ & 1.5 & 25 & 1.8 & 25 & 1.5 & 25 & 1.5 & 25 & (23) & (23) \\
\hline Folate equivalents $(\mu \mathrm{g})$ & 300 & 1000 & 300 & 1000 & 300 & 1000 & 300 & 1000 & (23) & (23) \\
\hline Vitamin $\mathrm{B}_{12}(\mu \mathrm{g})$ & 2.8 & - & $2 \cdot 8$ & - & $2 \cdot 8$ & - & 2.8 & - & (23) & (23) \\
\hline Vitamin C (mg) & 75 & - & 75 & - & 75 & - & 75 & - & (23) & (23) \\
\hline Vitamin D $(\mu \mathrm{g})$ & 3.3 & 50 & 3.3 & 100 & 3.3 & 100 & 3.3 & 100 & (23) & (23) \\
\hline Vitamin E (mg) & 10 & 300 & 10 & 300 & 8 & 300 & 8 & 300 & (23) & (23) \\
\hline Vitamin $\mathrm{K}$ total $(\mu \mathrm{g})$ & 120 & - & 120 & - & 90 & - & 90 & - & (23) & (23) \\
\hline \multicolumn{11}{|l|}{ Minerals/trace elements } \\
\hline $\mathrm{Ca}(\mathrm{mg})$ & 1000 & 2500 & 1100 & 2500 & 1000 & 2500 & 1100 & 2500 & (23) & (23) \\
\hline $\mathrm{Fe}(\mathrm{mg})$ & 9 & 25 & 9 & 25 & 15 & 25 & 9 & 25 & (23) & (23) \\
\hline $\mathrm{Na}(\mathrm{mg})$ & - & 2400 & - & 2400 & - & 2400 & - & 2400 & & (19) \\
\hline $\mathrm{K}(\mathrm{mg})$ & 3500 & - & 3500 & - & 3100 & - & 3100 & - & (23) & \\
\hline $\mathrm{Mg}(\mathrm{mg})$ & 350 & - & 350 & - & 280 & - & 280 & - & (23) & \\
\hline $\mathrm{Zn}(\mathrm{mg})$ & 9 & 25 & 9 & 25 & 7 & 25 & 7 & 25 & (23) & (23) \\
\hline Se $(\mu \mathrm{g})$ & 50 & 300 & 60 & 300 & 50 & 300 & 50 & 300 & (23) & (23) \\
\hline $\mathrm{Cu}(\mathrm{mg})$ & 0.9 & 5 & 0.9 & 5 & 0.9 & 5 & 0.9 & 5 & (23) & (23) \\
\hline lodine $(\mu \mathrm{g})$ & 150 & 600 & 150 & 600 & 150 & 600 & 150 & 600 & (23) & (23) \\
\hline \multicolumn{11}{|l|}{ Essential amino acid } \\
\hline Lysine $(\mathrm{g})$ & $2 \cdot 6$ & - & 2.6 & - & $2 \cdot 3$ & - & $2 \cdot 2$ & - & (24) & \\
\hline
\end{tabular}

Al, Adequate Intake.

"To convert to kJ, multiply kcal value by 4.184. 


\section{Linear programming and a metric for changes}

Optimisations were performed using Optimeal ${ }^{\circledR}$ (Blonk Consultants, Gouda, the Netherlands) ${ }^{(29)}$. In the optimisations we minimised changes to the current diet such that each nutritional and environmental constraint was satisfied.

Changes to the current diet were translated into a penalty score: a weighted sum of serving changes for each product. To capture dietary preferences in the model, the penalty weights were proportional to popularity and directionally dependent. We used the quantity (grams) consumed during the DNFCS as a proxy for popularity. The more popular a food, the lower its penalty weight for increased consumption and the higher its penalty weight for decreased consumption.

The model was designed to mimic consumer behaviour with regard to food choices. We reasoned that consumers do not like to change their diet, but that increases in the amounts of products they already consume will be perceived as less problematic than decreases. Also, if servings have to be added to meet a nutrient constraint, we assumed the most popular source would be better accepted. The total penalty score can thus be interpreted as a measure of distance between diets; it expresses how similar they are. If no changes are needed, the penalty score is zero. If changes are needed, the penalty score must be minimised during the optimisations in order to stay as close as possible to the current diet.

\section{Optimisation strategy}

We first calculated the solution closest to the current diet, considering only the nutritional requirements ('nutritionally optimised'). We then introduced a restriction on the $p$ ReCiPe value of the total diet and reduced it step by step, calculating a new optimised diet after each step until no solution was possible within the constraints.

\section{Results}

Figure 1 shows how the composition of the diet of men aged 31-50 years changed, first after introducing the nutritional requirements and then after gradually lowering the constraint on $p$ ReCiPe (for all other age-gender groups, see the online supplementary material, Supplemental Fig. 1). Figure 1 starts on the left with the current diet, then jumps to the 'nutritionally optimised', followed by all solutions with a lower $p$ ReCiPe. The composition of diets for men and women aged 31-50 years at three discrete points is shown in Table 2. Below, the results in each step are explained in detail.

\section{Current and 'nutritionally optimised' diets}

The current diets do not meet all nutrient requirements (Table 3). This was analysed for four age-gender groups: men/women aged 31-50 years and men/women aged 51-69 years. In all four groups, the intake of SFA was too high, whereas $\alpha$-linoleic acid, dietary fibre, EPA and DHA intakes were too low. This is consistent with the results of the DNFCS ${ }^{(15)}$. The main sources of SFA in the Dutch population are dairy products and meat and meat products. The low intake of Fe among women aged 31-50 years is worth highlighting, because it proved to be a

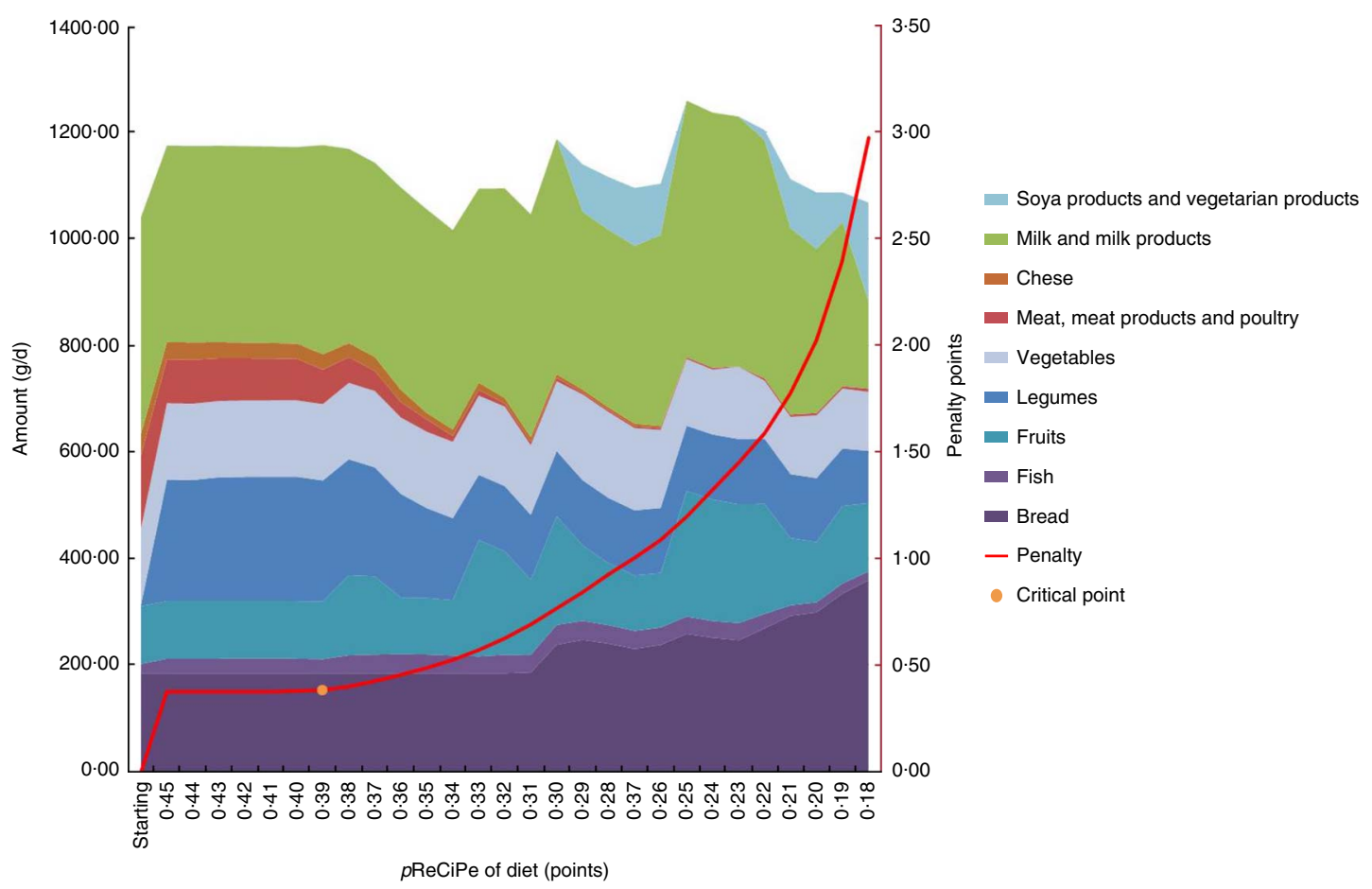

Fig. 1 Amounts of selected food groups and penalty score during the lowering of the constraint for overall environmental impact of the diet in $p R e C i P e$ points. Dutch men aged $31-50$ years 
( 2 Composition and environmental impacts ( $p$ ReCiPe, GHGE, FEU, LO) of current diets, diets optimised without environmental constraints ('nutritionally optimised') and diets at the 'critical point; ; as well as the contribution of each food group to the overall environmental impact of the total diet in $p \operatorname{ReCiPe}(\% p R e C i P e)$. Dutch men and women aged $31-50$ years

\begin{tabular}{|c|c|c|c|c|c|c|c|c|c|c|c|c|}
\hline & \multicolumn{6}{|c|}{ Men aged $31-50$ years } & \multicolumn{6}{|c|}{ Women aged $31-50$ years } \\
\hline & \multicolumn{2}{|c|}{ Current } & \multicolumn{2}{|c|}{ 'Nutritionally optimised' } & \multicolumn{2}{|c|}{ 'Critical point' } & \multicolumn{2}{|c|}{ Current } & \multicolumn{2}{|c|}{ 'Nutritionally optimised' } & \multicolumn{2}{|c|}{ 'Critical point' } \\
\hline & $g / d$ & $\% p \operatorname{ReCiPe}$ & $g / d$ & $\% p \operatorname{ReCiPe}$ & $g / d$ & $\% p \operatorname{ReCiPe}$ & $g / d$ & $\% p \operatorname{ReCiPe}$ & $g / d$ & $\% p \operatorname{ReCiPe}$ & $g / d$ & $\% p \mathrm{ReCiPe}$ \\
\hline \multicolumn{13}{|l|}{ Food group* } \\
\hline Beverages & 2298 & 16 & 2298 & 18 & 2298 & 21 & 2236 & 14 & 2236 & 15 & 2236 & 19 \\
\hline Bread & 185 & 4 & 185 & 5 & 185 & 6 & 141 & 4 & 141 & 4 & 141 & 5 \\
\hline Cereals and cereal products & 65 & 2 & 65 & 3 & 65 & 3 & 59 & 2 & 59 & 2 & 59 & 3 \\
\hline Cheese & 41 & 6 & 32 & 6 & 29 & 6 & 38 & 8 & 9 & 2 & 17 & 5 \\
\hline Eggs & 12 & 1 & 12 & 1 & 12 & 1 & 11 & 1 & 11 & 1 & 11 & 2 \\
\hline Fats, oils and savoury sauces & 73 & 6 & 73 & 7 & 73 & 7 & 53 & 6 & 49 & 5 & 50 & 6 \\
\hline Fish & 18 & 2 & 27 & 3 & 26 & 4 & 18 & 2 & 48 & 8 & 45 & 8 \\
\hline Fruits & 108 & 2 & 108 & 2 & 108 & 2 & 124 & 3 & 124 & 3 & 124 & 4 \\
\hline Legumes & 3 & 0 & 228 & 9 & 227 & 10 & 4 & 0 & 66 & 3 & 66 & 3 \\
\hline Meat, meat products and poultry & 137 & 33 & 82 & 22 & 65 & 11 & 91 & 29 & 80 & 27 & 43 & 9 \\
\hline Milk and milk products & 406 & 10 & 369 & 10 & 393 & 13 & 340 & 10 & 292 & 9 & 295 & 11 \\
\hline Mixed dishes & 2 & 0 & 2 & 0 & 2 & 0 & 4 & 0 & 4 & 0 & 4 & 0 \\
\hline Nuts, seeds and snacks & 36 & 4 & 16 & 2 & 16 & 2 & 30 & 4 & 24 & 3 & 25 & 4 \\
\hline Pastry and biscuits & 47 & 3 & 47 & 3 & 47 & 4 & 50 & 3 & 34 & 2 & 44 & 3 \\
\hline Potatoes & 128 & 2 & 128 & 2 & 128 & 3 & 81 & 1 & 81 & 2 & 81 & 2 \\
\hline Savoury bread spreads & 6 & 0 & 6 & 0 & 6 & 0 & 3 & 0 & 3 & 0 & 3 & 0 \\
\hline Soups & 64 & 4 & 8 & 0 & 8 & 0 & 62 & 6 & 172 & 6 & 151 & 5 \\
\hline Soya and vegetarian products & 0 & 0 & 0 & 0 & 0 & 0 & 9 & 0 & 74 & 1 & 9 & 0 \\
\hline Sugar, sweets and sweet sauces & 41 & 1 & 41 & 1 & 41 & 2 & 33 & 1 & 33 & 1 & 43 & 2 \\
\hline Vegetables & 143 & 4 & 143 & 4 & 143 & 5 & 139 & 4 & 175 & 6 & 180 & 8 \\
\hline Indicator of environmental impact & \multirow{2}{*}{\multicolumn{4}{|c|}{0.53}} & \multirow{3}{*}{\multicolumn{2}{|c|}{0.39}} & \multirow{2}{*}{\multicolumn{2}{|c|}{0.42}} & & & & \\
\hline$p \operatorname{ReCiPe}($ points/d) & & & & & & & & & \multicolumn{2}{|r|}{0.41} & \multicolumn{2}{|r|}{0.32} \\
\hline $\mathrm{GHGE}$ (kg CO 2 equivalents/d) & \multicolumn{2}{|c|}{4.6} & \multicolumn{2}{|r|}{3.7} & & & \multicolumn{2}{|r|}{3.6} & \multicolumn{2}{|c|}{3.6} & \multicolumn{2}{|r|}{$2 \cdot 8$} \\
\hline FEU (MJ/d) & \multirow{2}{*}{\multicolumn{2}{|c|}{$\begin{array}{r}39.8 \\
5.0\end{array}$}} & \multirow{2}{*}{\multicolumn{2}{|c|}{$\begin{array}{r}37.9 \\
4.1\end{array}$}} & \multirow{2}{*}{\multicolumn{2}{|c|}{$\begin{array}{r}36.3 \\
3.4\end{array}$}} & \multirow{2}{*}{\multicolumn{2}{|c|}{31.9}} & \multicolumn{2}{|c|}{$35 \cdot 4$} & \multicolumn{2}{|r|}{31.1} \\
\hline LO $\left(m^{2} \times\right.$ year $\left./ \mathrm{d}\right)$ & & & & & & & & & & 3.6 & & 2.6 \\
\hline
\end{tabular}

GHGE, greenhouse as emissions; FEU, fossil energy use; LO, land occupation

Corresponds with food groups in the Dutch Food Composition Database ${ }^{(20)}$. 
Table 3 Critical nutrients determining the outcome of optimal solutions in each age-gender group: men aged 31-50 years ( $\mathrm{m}$ ), men aged 51-69 years $(M)$, women aged 31-50 years $(\mathrm{w})$ and women aged 51-69 years $(\mathrm{W})$. The count shows how often a nutrient was either outside the model boundaries or critical

\begin{tabular}{|c|c|c|c|c|c|c|}
\hline & Current* & 'Nutritionally optimised' $\dagger$ & ‘Critical point’†,‡ & 'Half'†,§ & 'Minimum'†, $\|$ & Count \\
\hline a-Linoleic acid & $\mathrm{mMwW}$ & $\mathrm{mMwW}$ & mMwW & $\mathrm{mMwW}$ & mMwW & 20 \\
\hline Retinol activity equivalents & $\mathrm{mMwW}$ & $\mathrm{mMW}$ & $\mathrm{mMW}$ & $\mathrm{mMwW}$ & mMwW & 18 \\
\hline $\mathrm{Ca}$ & W & MwW & MwW & $\mathrm{mMwW}$ & mMwW & 15 \\
\hline $\mathrm{Na}$ & $\mathrm{mM}$ & $\mathrm{mMw}$ & $\mathrm{mMw}$ & $\mathrm{mMw}$ & mMwW & 15 \\
\hline $\mathrm{Se}$ & MwW & MW & $\mathrm{mMW}$ & $\mathrm{mMwW}$ & MwW & 15 \\
\hline Thiamin & $\mathrm{mMwW}$ & W & wW & $\mathrm{mMwW}$ & mMwW & 15 \\
\hline Fibre & mMwW & mMwW & mMwW & $\mathrm{mM}$ & & 14 \\
\hline $\mathrm{DHA}+\mathrm{EPA}$ & $\mathrm{mMwW}$ & $\mathrm{mMwW}$ & $\mathrm{mMW}$ & $\mathrm{m}$ & W & 13 \\
\hline Vitamin $\mathrm{B}_{6}$ & MwW & & $\mathrm{Mw}$ & MwW & mMwW & 12 \\
\hline SFA & $\mathrm{mMwW}$ & $\mathrm{mMW}$ & $\mathrm{mMwW}$ & M & & 12 \\
\hline Folate equivalents & $\mathrm{mMwW}$ & wW & wW & wW & & 10 \\
\hline Vitamin D & wW & w & wW & & $\mathrm{mMwW}$ & 9 \\
\hline Water & & & & $\mathrm{mMW}$ & $\mathrm{mMwW}$ & 7 \\
\hline $\mathrm{Fe}$ & w & w & w & w & w & 5 \\
\hline Niacin & & & & wW & wW & 4 \\
\hline Vitamin E & & & & & $\mathrm{mMwW}$ & 4 \\
\hline Carbohydrates & W & W & W & & & 3 \\
\hline Alcohol & W & W & W & & & 3 \\
\hline Riboflavin & & & & $\mathrm{m}$ & $\mathrm{m}$ & 2 \\
\hline Vitamin C & & & & $\mathrm{m}$ & $\mathrm{m}$ & 2 \\
\hline Fat total & & & & & w & 1 \\
\hline Vitamin $B_{12}$ & & & & & $\mathrm{~m}$ & 1 \\
\hline Vitamin $\mathrm{K}$ & & & & $\mathrm{M}$ & & 1 \\
\hline $\mathrm{K}$ & & & & & $\mathrm{m}$ & 1 \\
\hline
\end{tabular}

${ }^{\star}$ Nutrients outside boundaries in model (Table 1 ).

†Binding nutrient constraints.

$\ddagger$ Point where $\%$ change in penalty $/ \%$ change in $p \mathrm{ReCiPe}$ becomes elastic: diets become less acceptable.

$\S$ Environmental impact reduced to $50 \%$ of current diet.

\|Minimum environmental impact possible within nutrient and product constraints.

critical factor in the optimisations. The inadequacies in retinol activity equivalents and thiamin, on the other hand, were not consistent with the DNFCS and are a result of the limited number of products we could include: 207 instead of 1599 .

We initially optimised the diets without imposing environmental constraints. We call these diets 'nutritionally optimised' (Table 2). This made it possible to identify those changes necessary only to meet the nutritional requirements. We observed, for example, that in order to decrease the intake of SFA below the upper limit of $10 \%$ of energy, the main options are to reduce either cheese or meat and meat products. Only when $\mathrm{Fe}$ has to be increased at the same time, which is the case for women aged 31-50 years, is reducing cheese favoured over reducing meat and meat products, the latter being a source of Fe. In all groups, fish and legumes were increased. More fish was needed in order to meet the requirement for DHA+EPA. Legumes were added to supply thiamin, dietary fibre and folate, which were on average below nutritional requirements in the current diet. Soya drink fortified with riboflavin, vitamins $\mathrm{B}_{12}$ and $\mathrm{D}$ and $\mathrm{Ca}$ was added to diets for both groups of females, mainly to supply more vitamin D.

For men, 'nutritionally optimised' coincides with a substantial reduction in environmental impact, measured by both $p$ ReCiPe and GHGE. As noted above, meat and meat products were reduced because of their high SFA content. As this food group also has a high environmental impact, the 'nutritionally optimised' diet has a reduced environmental impact. Due to their higher Fe requirement, women aged 31-50 years cannot benefit from the same reduction strategy. Women aged 51-69 years, on the other hand, have a higher $\mathrm{Ca}$ requirement, which prevents a sharp decrease in cheese, another product with a high environmental impact.

\section{Solutions with reduced environmental impact}

After adding the constraint on $p$ ReCiPe, it was gradually reduced. The tighter the constraint, the more changes were required. Figure 1 shows on the left $y$-axis the amounts of each major food group in grams per day in diets with a lower $p$ ReCiPe than the current diet and on the right $y$-axis the penalty score, the metric for the amount of changes required to reach each value of $p$ ReCiPe. The steepness of this curve is captured by the elasticity of the penalty in relation to $p$ ReCiPe: \% change in penalty $/ \%$ change in $p$ ReCiPe. In Fig. 1 (and in the online supplementary material, Supplemental Fig. 1) we indicate the 'critical point', where the penalty curve moves from inelastic $(<1)$ to elastic $(>1)$. Beyond this point savings in environmental impact require proportionally more changes to the diet and/or the addition of less popular products. The more changes are required, the less acceptable diets will become for the average consumer. Before the 'critical point', the payback of any change is higher, i.e. 
changes are more effective. The 'critical point' occurs between a $21 \%$ and a $30 \%$ reduction of environmental impact, depending on gender and age. With extreme reductions, the penalty score is very high.

The curves are not smooth, as can be seen in the amounts of fruits and milk products. This indicates that within the solution space dissimilar diets can be very close to each other. We focus therefore on overall patterns.

After adding the constraint on $p$ ReCiPe (Table 2), nearly all reductions in environmental impact up to the 'critical point', also in women aged 31-50 years, came from reductions in the meat content of the diets and changes within the meat group. This implies that these are the most effective changes that can be made to the diet to decrease pReCiPe. This is further illustrated by Fig. 2, in which are plotted the contributions of food groups to the overall environmental impact. In the 'nutritionally optimised' diet the biggest contributions to environmental impact are from meat and meat products, alcoholic and non-alcoholic beverages, and milk and milk products. As mentioned earlier, initial savings were almost exclusively due to meat and meat products, in particular reductions in beef, which is the type of meat associated with the highest environmental impact $^{(30,31)}$. The proportion of the total environmental impact due to meat and meat products was $29-35 \%$ in the current diet and 22-30\% in the 'nutritionally optimised' diet.

Until the 'critical point' beverages were not affected, but at lower values of $p$ ReCiPe they were all reduced except for water and tea. This implies these changes have a higher penalty than those in meat.

Keeping the diets nutritionally adequate (meeting all requirements) while reducing environmental impact induced a shift to more environmentally efficient sources of nutrients. In most cases, more bread was added.

Milk and milk products, vegetables, fruit, legumes and fish remained relatively constant when the constraint on $p$ ReCiPe was lowered until the point where a solution was no longer possible.

\section{Critical nutrients}

Since the optimisation model minimises the changes needed to satisfy all nutritional constraints, the amount of the most critical nutrients remained exactly at the boundary after optimisation steps. Table 3 summarises which nutrients (mentioned in Table 1) were outside a boundary in the current diets and which ones were exactly at one of the boundaries, i.e. critical, after distinct optimisation steps.

Only $\alpha$-linoleic acid was critical in all cases, either too low in the current diet or at the lower boundary while reducing the environmental impact. Other frequently critical nutrients were retinol activity equivalents, $\mathrm{Ca}, \mathrm{Na}$, Se, thiamin and dietary fibre. As recognised before by Macdiarmid et $a l .{ }^{(10)}$, the requirement for $\mathrm{Fe}$ is an important factor. Only in the current diet of women aged $31-50$ years was the amount below the required intake and it remained a binding constraint during optimisations. The explanation for

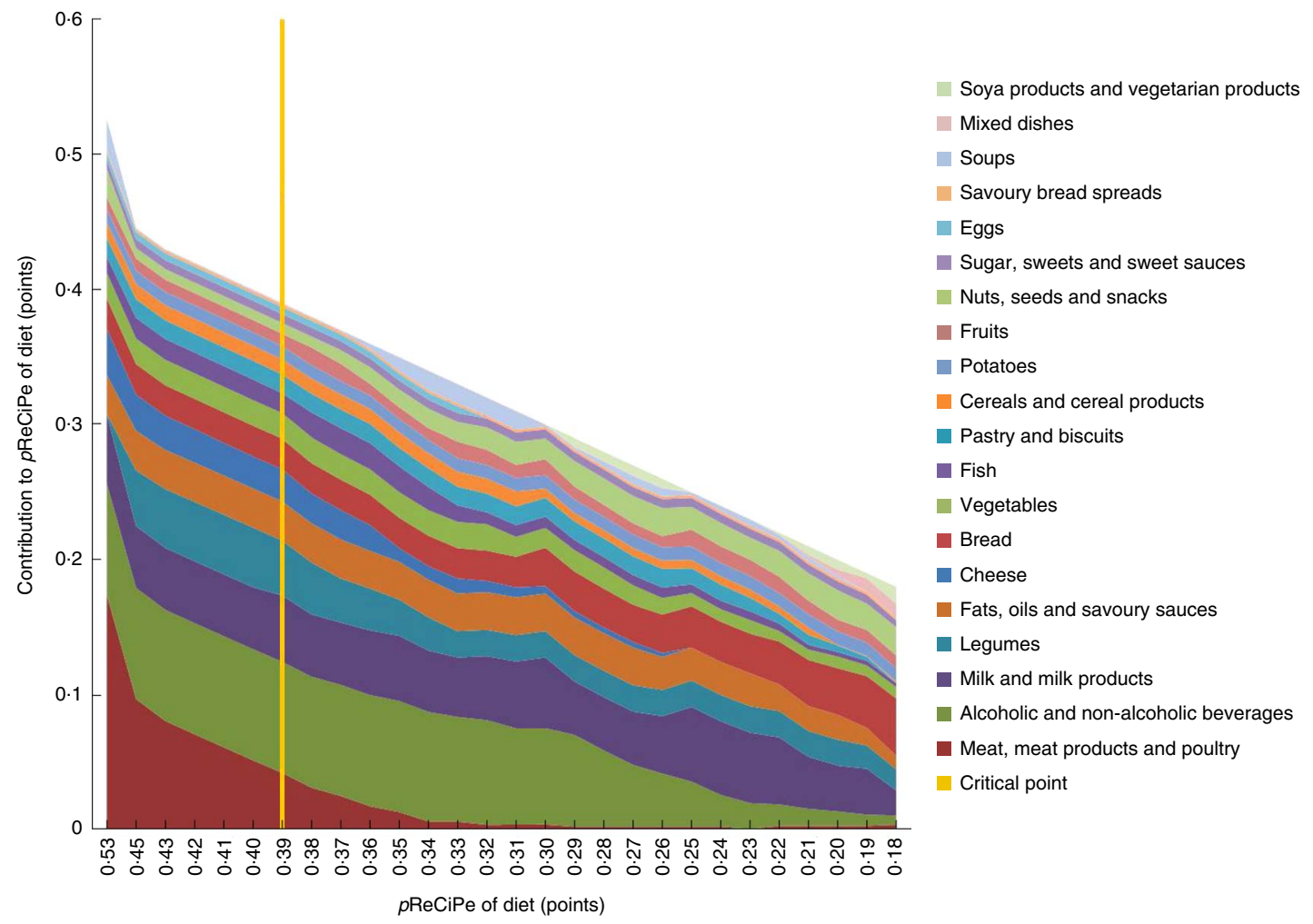

Fig. 2 Contributions made by food groups to the overall environmental impact ( $p \mathrm{ReCiPe}$ ) when the constraint on environmental impact is gradually lowered. Dutch men aged $31-50$ years 
this is that women of childbearing age have an increased demand for Fe: $15 \mathrm{mg} / \mathrm{d}$ instead of $9 \mathrm{mg} / \mathrm{d}$ (Table 1 ).

$\mathrm{Na}$ intake from the current diet of both groups of women is apparently below the upper tolerable limit. However, this is an underestimate because the amounts of salt added at home were not included in the DNFCS data, but recorded and reported separately ${ }^{(32)}$. Na was critical in most diets, which implies that more Na-containing products were present than would be the case if salt added at home would be included.

To the right of the 'critical point', EPA + DHA was no longer critical in any group, indicating that these diets contain a surplus of fish.

The average intake of essential amino acids was always more than twice the minimal requirement in all four groups, both in current diets and in 'nutritionally optimised' diets. None of them was ever binding in further optimisation steps.

\section{Discussion}

\section{General observations}

By using a weighted environmental indicator ( $p$ ReCiPe) instead of GHGE alone we avoided potentially undesirable negative effects on LO or FEU. Land occupation, in particular, is an important indicator for the impact of agriculture ${ }^{(33)}$.

The current study shows that it is possible to identify options for reducing the environmental impact of the current diet in the Netherlands that are both acceptable and effective. As Macdiarmid et al. ${ }^{(10)}$ have also shown for the UK, this is possible with substantial amounts of dairy products remaining in the diet. Wilson et al. ${ }^{(11)}$ studied solutions only with minimal GHGE (minus 81-87\%) in which both meat and fish were eliminated, but both milk powder and whole milk remained.

The results for other age-gender groups (see online supplementary material, Supplemental Fig. 1) are similar to the ones discussed here and do not lead to different conclusions.

Our methodology enabled us to distinguish between changes to the current diet necessary to meet nutrient requirements and changes induced by a tighter environmental constraint. This distinction is relevant when explaining the reasons behind dietary advice to the public. In this respect, reducing meat is a preferred option for both reasons, while the large increase in legumes is mainly due to nutrient requirements.

Recently, highly processed and ultra-processed foods have been criticised because they are more likely to be 'energy-dense nutrient poor ${ }^{\text {(34) }}$. We did not include the level of processing in our analysis, but implicitly the algorithm weighs the balance between nutrient density and environmental impact. Therefore it is plausible that the algorithm preferentially removes products with a low nutrient density during optimisation.

\section{Model limitations}

Our algorithm calculates the penalty score for deviations in a specific way: increasing linearly, asymmetrically and per serving. Other modelling options are possible, for instance giving a penalty only to reductions in amounts of products $^{(35)}$, using frequency instead of consumed weight as a popularity metric or applying quadratic programming ${ }^{(36)}$.

The current ReCiPe method does not include important global impacts such as overfishing ${ }^{(37)}$ and water stress ${ }^{(38)}$. This means that the overall environmental impact of increased fish intake is currently underestimated, although herring and mackerel are not overfished ${ }^{(39)}$. Still, our results show that for environmental impact reduction beyond the 'critical point', some diets contain more fish than strictly necessary to meet the requirement for EPA+ DHA. This can be attributed to other critical nutrients supplied by fatty fish, such as Se and vitamin D.

One of the limitations of our algorithm might be the linearity of the penalty score, which still allows solutions that seem quite far from the current diet. The observed increase in legumes is an example. If the penalty would increase quadratically, this increase would probably be more modest in favour of other product groups. When we limited legumes to the present level of intake, we observed increases in vegetables, meat replacers and bread to meet the requirements for fibre, thiamin and folate that were otherwise met by legumes.

Another limitation of the algorithm is that alcoholic and non-alcoholic beverages remained unaffected until the 'critical point'. This is explained by the savings potential of one serving of each available product. For water-rich products, such as beverages, this is much lower than for meat. The result is a higher penalty for a change of one serving.

\section{Data limitations}

Compared with other similar studies ${ }^{(10,11,40)}$, we included more products and used environmental impact data that were consistently modelled on a cradle-to-grave basis by ourselves. This consistent data set has been partially reviewed $^{(41)}$ and is also applied elsewhere ${ }^{(42)}$. Not taken into account was the variability in both environmental and nutrient data.

A limitation of our approach is that we had to use an approximation of the average diet observed in the DNFCS because we needed a reference point in the optimisation. This was a consequence of there being enough data available only to perform cradle-to-grave life cycle analyses of 207 products. Due to the condensing process the current diet is not a perfect match with the average of the DNFCS in terms of nutrient intake. This is most relevant for nutrients identified as critical during the optimisations, especially in the first step to obtain the 'nutritionally optimised' diet. However, because these discrepancies were corrected in this first optimisation step, they had only a minor influence on the conclusions of our study. 
Another limitation of our study is that we did not analyse the impact on the affordability of the diet, which could be important for acceptance by lower-income groups ${ }^{(43,44)}$.

\section{Main results}

Our main finding is that, up to the 'critical point', the preferred environmental savings come almost exclusively from consuming less meat, especially beef. This supports a flexitarian or semi-vegetarian food pattern ${ }^{(6,42)}$. We also found that age and gender affected the environmental impact of the current diet and the content of the "nutritionally optimised' diets in particular. The latter was related to differences in nutrient requirements, for instance in Fe (women of fertile age) and Ca (elderly women). This illustrates the need for tailored public advice on sustainable diets. The difference in overall environmental impact between current diets of men and women has been observed before ${ }^{(8,45)}$ and is mainly related to the differences in energy intake and to a lesser extent to differences in composition ${ }^{(46)}$.

Beyond that 'critical point' our study is in line with findings of Macdiarmid et al. ${ }^{(10)}$, who found that meat and eggs decreased, while bread, legumes and fish increased. In our analyses, however, the increased amount of legumes and fish is mainly due to nutritional requirements. Macdiarmid et al. also found more fruits and vegetables, and observed a similar trend in dairy products, which remained fairly constant. We did not find any significant increases in vegetables or fruits.

Our results indicate that alcoholic and non-alcoholic beverages are responsible for $14-16 \%$ of the total environmental impact of the current diet in the Netherlands, which is close to previous estimates ${ }^{(42)}$. Macdiarmid et al. excluded beverages, but our study shows they have a substantial reduction potential. The only limitation is that it requires more changes to the diet to fulfil the potential in comparison to meat.

As mentioned before, the present study shows that dairy products and fatty fish remain part of diets with a reduced environmental impact. Our findings indicate that dairy has a favourable balance between nutrient density and environmental impact, as has been suggested before ${ }^{(11,47)}$.

Fish cannot be replaced, primarily because it is the exclusive dietary source of EPA and DHA. The Dutch Health Council has set a requirement of $450 \mathrm{mg} / \mathrm{d}^{(19)}$, in line with evidence in support of high fish consumption ${ }^{(48)}$. At the same time, it was also noted that this requirement may conflict with environmental goals ${ }^{(49)}$.

As amounts of meat, cheese and eggs in the diet decrease, it is plausible that intakes of vitamin $\mathrm{B}_{12}$, Ca, lysine and Fe might become critical. We found this true only for $\mathrm{Ca}$ and $\mathrm{Fe}$, and the latter only in women of childbearing age. Other desirable nutrients that were often critical include $\alpha$-linoleic acid, retinol activity equivalents, Se, thiamin and dietary fibre.

As in other studies in this area ${ }^{(44,50)}$, our findings depend on the national and international nutrient requirements used. By covering requirements for this wide array of nutrients we avoided undesirable omissions in diets, such as the elimination of fish ${ }^{(11)}$.

Our results also indicate that a single focus on replacing protein of animal origin is far too limited. Neither the total amount of protein nor any specific essential amino acid was critical, whereas other nutrients from products of animal origin, such as $\mathrm{Ca}$, Se and $\mathrm{Fe}$, were.

\section{Conclusions}

In the present paper we have introduced a structured approach for finding the most effective and acceptable mitigation options. We have shown that age and gender influence the outcome of optimisations. Our findings could be useful for preparing advice to the public.

Applying the linear programming algorithm that minimises the distance to the current diet, we confirmed earlier observations that reducing meat consumption is an effective way to lower the environmental impact of diets. Removing fish and dairy products do not seem to be effective options, whereas consumers can substantially reduce the environmental impact of their diet by drinking less alcoholic and non-alcoholic beverages. Further research can be directed to investigating the robustness of these results by applying other optimisation techniques, such as quadratic programming, and different options for the penalty and the metric for popularity. Another issue to be investigated is the effect of data variability in nutrient content and environmental impacts.

\section{Acknowledgements}

Acknowledgements: The authors are grateful to Corné van Dooren (Netherlands Nutrition Centre, The Hague) for his valuable support in defining the nutritional boundaries in the model. Financial support: G.F.H.K., M.T. and H.B. received a financial grant from FrieslandCampina. FrieslandCampina had no role in the design, analysis or writing of this article. P.v.t.V. did not receive any financial support for his contribution. Conflict of interest: G.F.H.K. and H.B. are employed by Blonk Consultants, a private company doing projects for non-governmental organisations, private companies in the animal feed industry, the food and beverage industry, and public institutions. Some customers may benefit from the outcome of this study, others may not. At the time of the study M.T. was employed by Blonk Consultants. P.v.t.V. has no conflicts of interest. Authorship: G.F.H.K., M.T. and H.B. formulated the research questions and designed the study; G.F.H.K. and M.T. carried out study and analysed the data. All the authors participated in the interpretation of the results and in the writing of the article. Ethics of human subject participation: Not applicable. 


\section{Supplementary material}

To view supplementary material for this article, please visit http://dx.doi.org/10.1017/S1368980017000349

\section{References}

1. Tukker A, Huppes G, Guinée J et al. (2006) Environmental Impact of Products (EIPRO). Analysis of the Life Cycle Environmantal Impacts Related to the Final Consumption of the EU-25. Seville: European Commission, Joint Research Centre, Institute for Prospective Technological Studies.

2. Vermeulen SJ, Campbell BM \& Ingram JSI (2012) Climate change and food systems. Annu Rev Environ Resour 37, 195-222.

3. Hallström E, Carlsson-Kanyama A \& Börjesson P (2015) Environmental impact of dietary change: a systematic review. J Clean Prod 91, 1-11.

4. Auestad N \& Fulgoni VL 3rd (2015) What current literature tells us about sustainable diets: emerging research linking dietary patterns, environmental sustainability, and economics. Adv Nutr 6, 19-36.

5. Tukker A, Goldbohm RA, de Koning A et al. (2011) Environmental impacts of changes to healthier diets in Europe. Ecol Econ 70, 1776-1788.

6. Soret S, Mejia A, Batech M et al. (2014) Climate change mitigation and health effects of varied dietary patterns in real-life settings throughout North America. Am J Clin Nutr 100, Suppl. 1, 490S-495S.

7. Tom MS, Fischbeck PS \& Hendrickson CT (2015) Energy use, blue water footprint, and greenhouse gas emissions for current food consumption patterns and dietary recommendations in the US. Environ Syst Decis 36, 92-103.

8. Vieux F, Soler LG, Touazi D et al. (2013) High nutritional quality is not associated with low greenhouse gas emissions in self-selected diets of French adults. Am J Clin Nutr 97, 569-583.

9. Temme EH, van der Voet $\mathrm{H}$, Thissen JT et al. (2013) Replacement of meat and dairy by plant-derived foods: estimated effects on land use, iron and SFA intakes in young Dutch adult females. Public Health Nutr 16, 1900-1907.

10. Macdiarmid JI, Kyle J, Horgan GW et al. (2012) Sustainable diets for the future: can we contribute to reducing greenhouse gas emissions by eating a healthy diet? Am J Clin Nutr 96, 632-639.

11. Wilson N, Nghiem N, Ni Mhurchu C et al. (2013) Foods and dietary patterns that are healthy, low-cost, and environmentally sustainable: a case study of optimization modeling for New Zealand. PLoS One 8, e59648.

12. Wolf O, Pérez-Domínguez I, Rueda-Cantuche JM et al. (2011) Do healthy diets in Europe matter to the environment? A quantitative analysis. J Policy Model 33, 8-28.

13. Westhoek H, Rood T, van den Berg M et al. (2011) The Protein Puzzle: The Consumption and Production of Meat, Dairy and Fish in the European Union. The Hague: PBL Netherlands Evironmental Assessment Agency.

14. Stehfest E, Bouwman L, Vuuren DP et al. (2009) Climate benefits of changing diet. Clim Change 95, 83-102.

15. Van Rossum CTM, Fransen HP, Verkaik-Kloosterman J et al. (2011) Dutch National Food Consumption Survey 20072010. Bilthoven: RIVM

16. Freisling H, Fahey MT, Moskal A et al. (2010) Regionspecific nutrient intake patterns exhibit a geographical gradient within and between European countries. J Nutr 140, 1280-1286.

17. Tukker A, Bausch-Goldbohm S, Verheijden $\mathrm{M}$ et al. (2009) Environmental Impacts of Diet Changes in the EU.
Seville: European Commission, Joint Research Centre, Institute for Prospective Technological Studies.

18. National Institute for Public Health and the Environment (2012) Consumption_food_nut.dat Version 20111125, part of the Dutch National Food Consumption Survey 20072010. Bilthoven: RIVM.

19. Health Council of the Netherlands (2006) Guidelines for a Healthy Diet 2006. Publication no. 2006/21. The Hague: Health Council of the Netherlands.

20. National Institute for Public Health and the Environment (2011) NEVO-online version 2011/3.0. http://nevo-online. rivm.nl/ (accessed January 2013).

21. US Department of Agriculture (2012) Release 25 of the USDA National Nutrient Database for Standard Reference. http://www.ars.usda.gov/Services/docs.htm?docid = 22771 (accessed May 2013)

22. Health Council of the Netherlands (2001) Dietary Reference Intakes: Energy, Proteins, Fats, and Digestible Carbobydrates. Publication no. 2001/19R. The Hague: Health Council of the Netherlands.

23. Netherlands Nutrition Centre (2014) Recommendations for Vitamins, Minerals and Trace Elements. The Hague: Netherlands Nutrition Centre.

24. World Health Organization, Food and Agriculture Organization of the United Nations \& United Nations University (2007) Protein and Amino Acid Requirements in Human Nutrition. Report of a Joint FAO/WHO/UNU Expert Consultation. WHO Technical Report Series no. 935. Geneva: WHO.

25. Kramer GFH, Broekema R, Tyszler M et al. (2013) Comparative LCA of Dutch Dairy Products and Plant-Based Alternatives. Gouda: Blonk Consultants.

26. Van Westerhoven S \& Steenhuizen F (2010) Determination of Food Losses by Households and Catering in the Netherlands. Amsterdam: CREM.

27. Goedkoop M, Heijungs R, Huijbregts M et al. (2013) ReCiPe 2008: A Life Cycle Impact Assessment Method Which Comprises Harmonised Category Indicators at the Midpoint and the Endpoint Level. First edition (revised). The Hague: Ministry of Housing, Spatial Planning and Environment.

28. Sevenster M, Blonk H \& Van der Flier S (2010) Environmental Analyses of Food and Food Waste. Delft: CE Delft, Blonk Milieu Advies.

29. Tyszler M, Kramer G \& Blonk H (2014) Comparing apples with oranges: on the functional equivalence of food products for comparative LCAs. Int J Life Cycle Assess 19, 1482-1487.

30. Gerber PJ, Steinfeld H, Henderson B et al. (2013) Tackling Climate Change Through Livestock - A Global Assessment of Emissions and Mitigation Opportunities. Rome: FAO.

31. Eshel G, Shepon A, Makov T et al. (2014) Land, irrigation water, greenhouse gas, and reactive nitrogen burdens of meat, eggs, and dairy production in the United States. Proc Natl Acad Sci U S A 111, 11996-12001.

32. Van Rossum CTM, Buurma-Rethans EJM, Fransen H. et al. (2012) Salt Consumption of Children and Adults in the Netherlands - Results from the Dutch National Food Consumption Survey 2007-2010. RIVM rapport 350050007/ 2012. Bilthoven: RIVM.

33. Searchinger T, Hanson C, Ranganathan J et al. (2013) Creating a Sustainable Food Future - World Resources Report 2013-14: Interim Findings. Washington, DC: World Resources Institute.

34. Harray A, Boushey C, Pollard C et al. (2015) A novel dietary assessment method to measure a healthy and sustainable diet using the mobile food record: protocol and methodology. Nutrients 7, 5375-5395.

35. Maillot M, Vieux F, Amiot MJ et al. (2010) Individual diet modeling translates nutrient recommendations into realistic and individual-specific food choices. Am J Clin Nutr 91, $421-430$. 
36. Arnoult MH, Jones PJ, Tranter RB et al. (2010) Modelling the likely impact of healthy eating guidelines on agricultural production and land use in England and Wales. Land Use Policy 27, 1046-1055.

37. Avadí A \& Fréon P (2013) Life cycle assessment of fisheries: a review for fisheries scientists and managers. Fish Res $\mathbf{1 4 3}$, 21-38.

38. Pfister S, Koehler A \& Hellweg S (2009) Assessing the environmental impacts of freshwater consumption in LCA. Environ Sci Technol 43, 4098-4104.

39. Emanuelsson A, Ziegler F, Pihl L et al. (2014) Accounting for overfishing in life cycle assessment: new impact categories for biotic resource use. Int J Life Cycle Assess 19, 1156-1168.

40. Vieux F, Darmon N, Touazi D et al. (2012) Greenhouse gas emissions of self-selected individual diets in France: changing the diet structure or consuming less? Ecol Econ $\mathbf{7 5}$, 91-101.

41. Blonk Agri-footprint BV (2014) Agri-Footprint - Part 1 Methodology and Basic Principles - Version 1.0. Gouda: Blonk Agri-footprint BV.

42. Biesbroek S, Bueno-de-Mesquita BH, Peeters PHM et al. (2014) Reducing our environmental footprint and improving our health: greenhouse gas emission and land use of usual diet and mortality in EPIC-NL: a prospective cohort study. Environ Health 13, 27.

43. Barosh L, Friel S, Engelhardt K et al. (2014) The cost of a healthy and sustainable diet - who can afford it? Aust NZJ Public Health 38, 7-12.
44. Masset G, Soler L-G, Vieux F et al. (2014) Identifying sustainable foods: the relationship between environmental impact, nutritional quality, and prices of foods representative of the French diet. J Acad Nutr Diet 114, 862-869.

45. Meier T \& Christen O (2012) Gender as a factor in an environmental assessment of the consumption of animal and plantbased foods in Germany. Int J Life Cycle Assess 17, 550-564.

46. Temme EHM, Toxopeus IB, Kramer GFH et al. (2015) Greenhouse gas emission of diets in the Netherlands and associations with food, energy and macronutrient intakes. Public Health Nutr 18, 2433-2445.

47. Smedman $\mathrm{A}$, Lindmark-Månsson $\mathrm{H}$, Drewnowski A et al. (2010) Nutrient density of beverages in relation to climate impact. Food Nutr Res 2010, 54.

48. Kromhout D, Yasuda S, Geleijnse JM et al. (2012) Fish oil and omega-3 fatty acids in cardiovascular disease: do they really work? Eur Heart J 33, 436-443.

49. Health Council of the Netherlands (2011) Guidelines for a Healthy Diet: The Ecological Perspective. Publication no. 2011/08. The Hague: Health Council of the Netherlands.

50. Heller MC \& Keoleian GA (2012) A novel nutrition-based functional equivalency metric for comparative life cycle assessment of food. Presented at the 8th International Conference on LCA in the Agri-Food Sector, Rennes, France, 2-4 October 2012.

51. Health Council of the Netherlands (2006) Guideline for Dietary Fibre Intake. The Hague: Health Council of the Netherlands. 